\title{
Paradoxical Reaction In The Form Of New Pulmonary Mass During Anti-Tuberculosis Treatment: A Case Series And Literature Review
}

This article was published in the following Dove Press journal: Infection and Drug Resistance

\author{
Ting Guo ${ }^{1-3}$ \\ Wei Guo ${ }^{1-3}$ \\ Min Song ${ }^{1-3}$ \\ Shanshan $\mathrm{Ni}^{1-3}$ \\ Man Luo ${ }^{1-3}$ \\ Ping Chen ${ }^{1-3}$ \\ Hong Peng ${ }^{1-3}$ \\ 'Department of Respiratory and Critical \\ Care Medicine, The Second Xiangya \\ Hospital of Central-South University, \\ Changsha, Hunan 4I00II, People's \\ Republic of China; ${ }^{2}$ Research Unit of \\ Respiratory Disease, Central-South \\ University, Changsha, Hunan 4100II, \\ People's Republic of China; ${ }^{3}$ The \\ Respiratory Disease Diagnosis and \\ Treatment Center of Hunan Province, \\ Changsha, Hunan 4I00II, People's \\ Republic of China
}

Introduction: Paradoxical reaction refers to deterioration of the original tuberculosis lesions or emergence of new infiltrative lesions during anti-tuberculosis treatment. The common manifestations of paradoxical reaction include new pleural effusion, cerebral tuberculosis and lymphadenitis. Paradoxical reaction manifested by new pulmonary mass is rare.

Patients and methods: This article summarizes and analyzes the clinical manifestations, chest CT, laboratory findings, treatments, pathological biopsy results of five patients diagnosed as paradoxical reaction in the form of new pulmonary mass. A literature review related to paradoxical reaction was conducted.

Results: Five patients diagnosed as pulmonary tuberculosis or tuberculous pleuritis received systematic anti-tuberculosis treatmensssts. New pulmonary masses were found by CT scans during the follow-ups. The patients were negative for tumor markers, examination of rheumatoid connective tissue disease and G/GM test. The original anti-tuberculosis treatments were continued. All of the masses were diminished gradually.

Conclusion: Paradoxical reaction needs to be taken into consideration when a new pulmonary mass occurs during anti-tuberculosis treatments. The diagnosis should be based on the patients' clinical manifestations, laboratory results, imaging examinsssations and lung biopsy examinations. The original anti-tuberculosis therapy can be continued in patients without severe clinical symptoms. A close follow-up is needed.

Keywords: tuberculosis, paradoxical reaction, mass

\section{Introduction}

Paradoxical reaction (PR) is defined as worsening of the existing disease or new tuberculosis lesions during anti-tuberculosis therapy. Drug resistance, adherence issues, secondary infection, malignancy and rheumatological disorders should be excluded. ${ }^{1}$ The common clinical manifestation of PR includes recurring symptoms such as fever, cough and polypnea, radiological deterioration, appearance of pleural effusion or ascites, new intracranial tuberculosis and the progression of lymphadenitis. ${ }^{2}$ PR can occur from one week to several months after the initiation of anti-tuberculosis treatments. ${ }^{3,4}$ It is more frequent in patients with extrapulmonary or disseminated tuberculosis. ${ }^{5}$ The incidence of PR is $2.4-23 \%$ in HIV-negative patients. ${ }^{6,7}$ The morbidity of PR is $11-36 \%$ in individuals co-infected with HIV who recently received highly active antiretroviral therapy (HAART) initiated. ${ }^{8,9}$ Here, we present five cases which were diagnosed as pulmonary tuberculosis or tuberculous pleuritis at first and were received standard treatments. A routine CT
Correspondence: Hong Peng

Department of Respiratory and Critica

Care Medicine, The Second Xiangya

Hospital Of Central-South University

No. 139 Renmin Middle Road,

Changsha, Hunan 4l00II, People's

Republic of China

Tel +86-I3807494486

Fax +86 73I-85295I47

Email penghong66@csu.edu.cn 
scan examination revealed newly formed pulmonary mass during the follow-up visit, which was verified as paradoxical reaction. PR manifested by new pulmonary mass is uncommon. We make a literature review to have a better understanding of PR.

\section{Patients And Methods}

We collected the information of clinical manifestations, chest computerized tomography (CT) scans, laboratory findings, treatments, pathological biopsy results from five patients diagnosed as paradoxical reaction in the form of new pulmonary mass. The features of this phenomena were summarized and analyzed and a follow-up was made. A literature review related to paradoxical reaction was conducted.

\section{Case Presentation Case I}

A 52-year-old female with a history of anti-tuberculosis therapy for six months was referred to our department because a new mass appeared on chest CT during a regular routine checkup. Six months ago, the patient complained of right chest pain for one year. At that time, the CT showed a $1.7 \times 1.4 \mathrm{~cm}$ nodule in the right-superior pulmonary lobe (Figure 1A and B). There were no apparent lesions in the right-inferior lobe (Figure 2A and B). She denied history of smoking, malignancy, diabetes and other serious illness. Since both interferon-gamma release assays (IGRAs) and tuberculin skin tests were positive, a diagnosis of pulmonary tuberculosis was made. The patient started an induction chemotherapy consisting of isoniazid, rifampicin, ethambutol, pyrazinamide and levofloxacin. Due to the liver damage, the regimens were changed to isoniazid, rifapentine and ethambutol. Her symptoms were gradually improved. A week before this admission, CT scans revealed a new occupying lesion $(3.4 \mathrm{~cm} \times 2.3 \mathrm{~cm})$ in the right-inferior lobe (Figure 2C and D), whereas the original nodule located in the superior lobe demonstrated improvement (Figure 1C and D). The patient denied symptoms of fever, cough, chest pain or weight loss. White blood cell (WBC) counts were $4.28 \times 10^{9} / \mathrm{L}$ with $17.80 \%$ lymphocytes. Tuberculin skin test remained positive. Other laboratory results including erythrocyte sedimentation rate (ESR), C-reactive protein (CRP), tumor markers, galactomannan test (GM-test), $(1,3)-\beta$-D glucan test (G-test), autoantibodies related to connective tissue disease were within the normal ranges. HIV test was negative. CT-guided percutaneous lung biopsy demonstrated caseating granulomas (Figure 3). The patient was diagnosed as paradoxical


Figure I Case I. CT findings in the right-superior pulmonary lobe. (A and B) A I.7 $\times 1.4 \mathrm{~cm}$ nodule was found at the initial diagnosis of pulmonary tuberculosis. (C and $\mathbf{D})$ The nodule was almost absorbed after six months of chemotherapy. 




Figure 2 Case I. Time course of CT findings in the right-inferior pulmonary lobe. (A and $\mathbf{B})$ There was no obvious mass at the initial diagnosis of pulmonary tuberculosis. (C and D) A new occupying lesion in diameter of $3.4 \mathrm{~cm} \times 2.3 \mathrm{~cm}$ appeared after six months of chemotherapy, and its margin was irregular. (E and $\mathbf{F}$ ) The mass was diminished to $1.5 \mathrm{~cm} \times 1.3 \mathrm{~cm}$ seven months after the initial diagnosis. (G and $\mathbf{H})$ The mass was $0.9 \mathrm{~cm} \times 1.1 \mathrm{~cm}$ nine months after the initial diagnosis. 


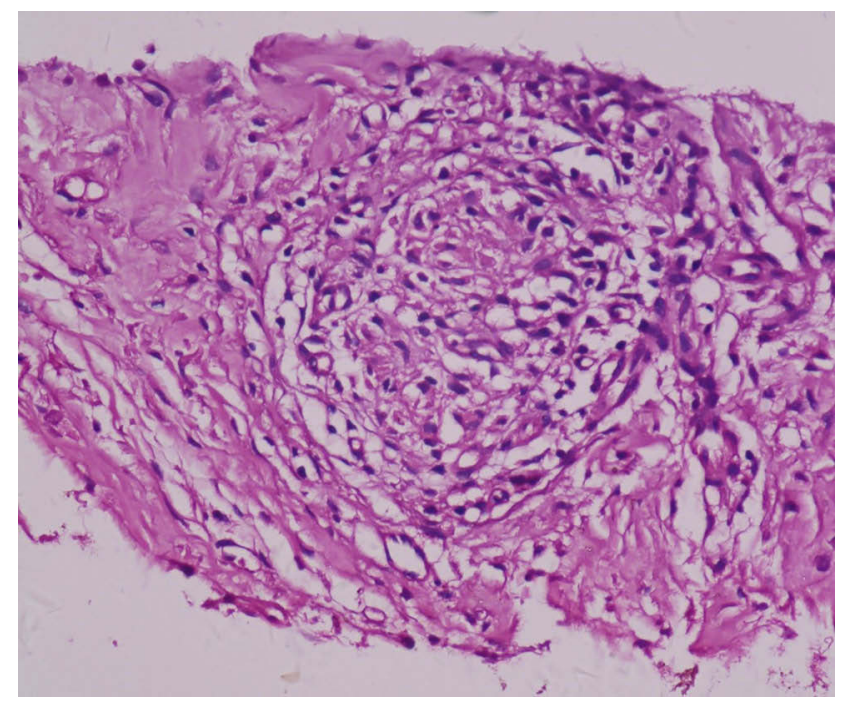

Figure 3 Case I. CT-guided percutaneous lung biopsy shows caseous necrosis and granulomatosis surrounded by epithelioid and multinucleated giant cells. Hematoxylin and eosin, $\times 400$.

reaction and was continued on anti-tuberculosis therapy. The size of new pulmonary mass was reduced to $1.5 \mathrm{~cm} \times$ $1.3 \mathrm{~cm}$ one month later (Figure $2 \mathrm{E}$ and $\mathrm{F}$ ) and was further reduced to $0.9 \mathrm{~cm} \times 1.1 \mathrm{~cm}$ (Figure $2 \mathrm{G}$ and $\mathrm{H}$ ) three months later. Currently, the patient is asymptomatic, and the original therapy continues.

\section{Case 2}

A 35-year-old female was admitted to a community hospital because of polypnea, cough, sputum and intermittent fever four months ago. She has a medical history of HBV infection. The patient denied a history of smoking. Local CT scans revealed right pleural effusion and pleural thickening.
Diagnostic thoracentesis showed tuberculous exudative fluid. A diagnosis of tuberculous pleuritis was speculated. The patient started anti-tuberculosis therapy with isoniazid, rifampicin, ethambutol and pyrazinamide. The patient's symptoms were gradually relieved, and the therapy was continued. Two weeks before, the patient developed cough and sputum. CT scans revealed a $3.9 \mathrm{~cm} \times 2.9 \mathrm{~cm}$ mass in the right middle and inferior pulmonary lobe with no pleural effusion (Figure 4). WBC was $7.03 \times 10^{9} / \mathrm{L}$ with $80.90 \%$ neutrophils. HGB was $122 \mathrm{~g} / \mathrm{L}$. Results of examinations of ESR, CRP, liver function, tumor markers, GM-test, G-test and autoantibodies related to connective tissue disease were normal. HIV test was negative. IGRAs and tuberculin skin test were positive. Sputum smears and culture were negative for acid-fast bacilli. CT-guided percutaneous lung biopsy showed plentiful infiltration of epithelioid cells and lymphocytes (Figure 5). The patient was diagnosed as PR paradoxical and was continued on the original anti-tuberculosis therapy. She recovered well during the follow-up. Local CT scans showed that the pulmonary mass was diminished three months later.

\section{Case 3}

A 17-year-old female was diagnosed as pulmonary tuberculosis during a physical examination at the local hospital six months ago. She adopted a therapy of isoniazid, rifampicin, ethambutol and pyrazinamide. During the follow-up, CT scans showed that the original lesions were absorbed gradually while a new $1.4 \mathrm{~cm} \times 0.8 \mathrm{~cm}$ (Figure $6 \mathrm{~A}$ and $\mathrm{B}$ ) nodule appeared in the left-superior lobe six months later. The patient denied symptoms of fever, cough, chest pain or weight loss. Laboratory results of ESR, CRP, liver
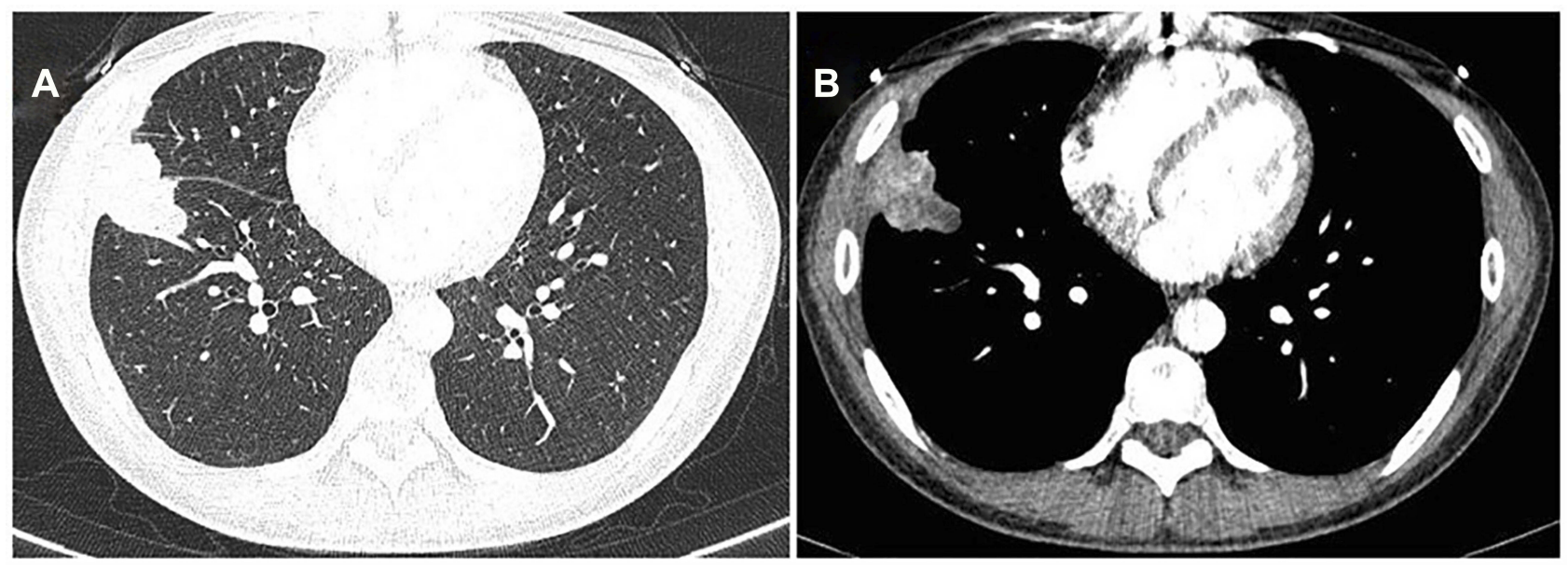

Figure 4 Case 2. CT findings in the right middle and inferior pulmonary lobe. (A and B) A $3.9 \mathrm{~cm} \times 2.9 \mathrm{~cm}$ lobulated mass without pleural effusion was found was after four months of anti-tuberculosis treatment. 


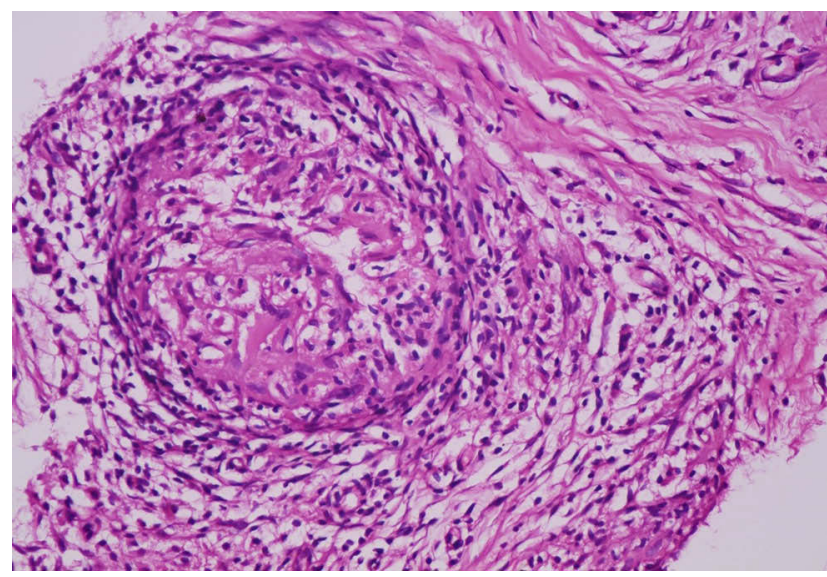

Figure 5 Case 2. CT-guided percutaneous lung biopsy shows plentiful infiltration of epithelioid cells and lymphocytes. Hematoxylin and eosin, $\times 400$.

function, tumor markers, GM-test, G-test and autoantibodies related to connective tissue disease were normal. HIV test was negative. IGRAs and tuberculin skin test were positive. CT-guided percutaneous lung biopsy showed tuberculous granuloma. The patient was diagnosed as PR and was continued on the original anti-tuberculosis therapy. The pulmonary mass was reduced to $1.0 \mathrm{~cm} \times 0.3 \mathrm{~cm}$ (Figure 6C and D) two months later.

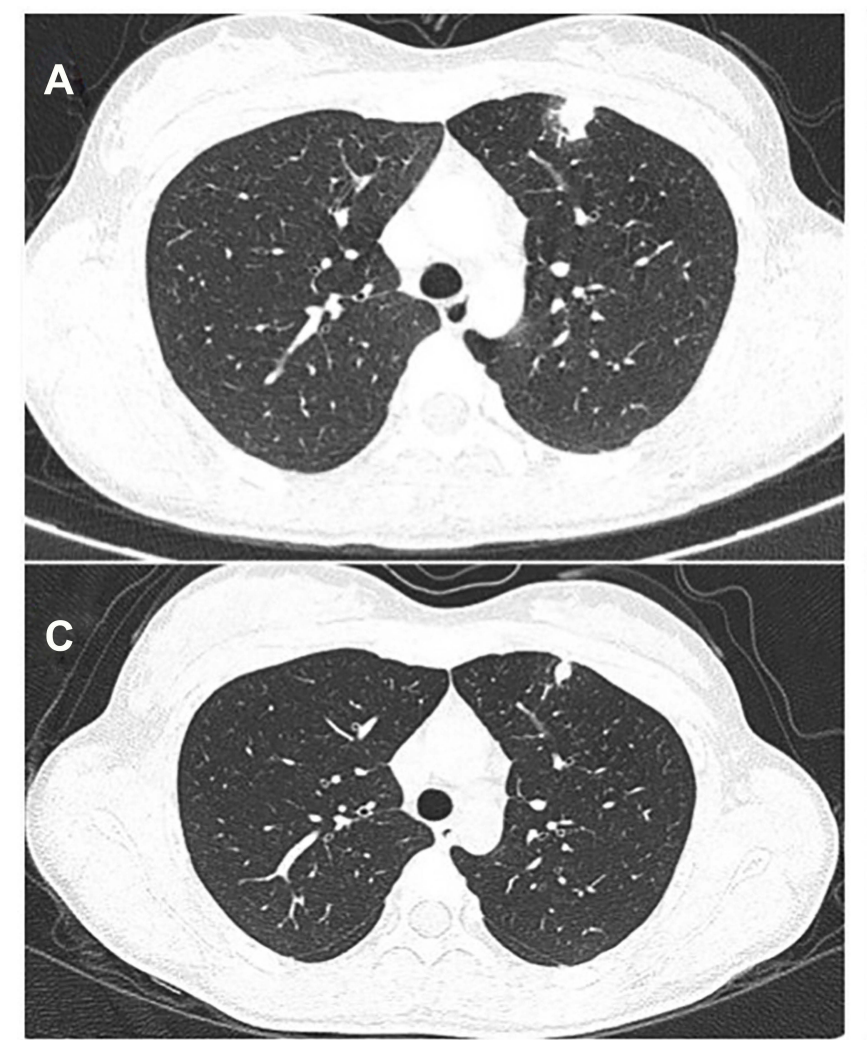

\section{Case 4}

A 35-year-old female complained of right chest pain for several months and was diagnosed as tuberculous pleuritis at the local hospital. A therapy consisting of isoniazid, rifampicin, ethambutol and pyrazinamide was conducted. The patient's symptom was gradually alleviated. In a routine checkup after three months, a mass measuring $3.3 \mathrm{~cm} \times$ $2.0 \mathrm{~cm}$ in the right-inferior lobe was discovered (Figure 7). Tumor markers, GM-test, G-test, autoantibodies related to connective tissue disease and HIV test were negative. Tuberculin skin test was positive. The patient refused CTguided percutaneous lung biopsy. PR was speculated and the patient continued on the original therapy. Through a follow-up by phone, the patient appeared to recover well and the mass was absorbed after eight months.

\section{Case 5}

A 40-year-old female was diagnosed as tuberculous pleuritis and started a standardized therapy with isoniazid, rifampicin, ethambutol and pyrazinamide. A $2.0 \mathrm{~cm} \times 1.5 \mathrm{~cm}$ new mass appeared in the right middle lobe after two months (Figure 8). Tuberculin skin test was positive. Other

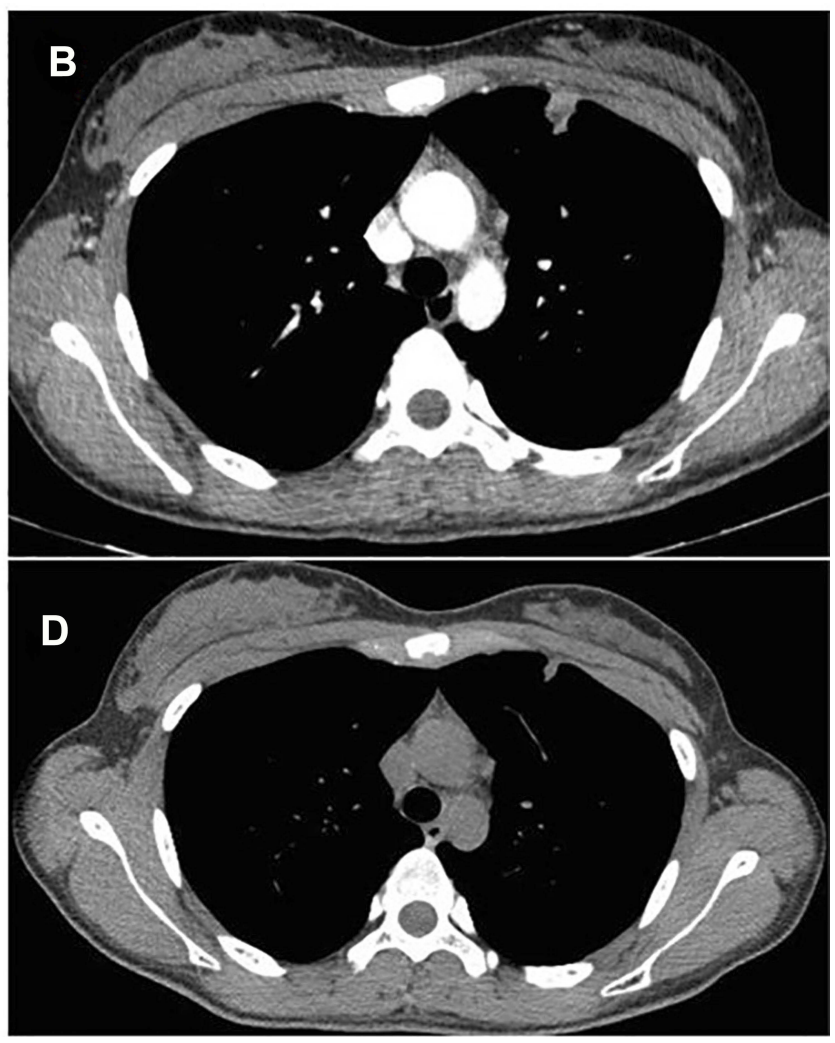

Figure 6 Case 3. Time course of CT findings in the left-superior pulmonary lobe. (A and B) A new occupying lesion in diameter of $1.4 \mathrm{~cm} \times 0.8 \mathrm{~cm}$ appeared after six months of chemotherapy with irregular margin and central low density. (C and $\mathbf{D})$ The nodule was diminished to $1.0 \mathrm{~cm} \times 0.3 \mathrm{~cm}$ eight months after the initial diagnosis. 

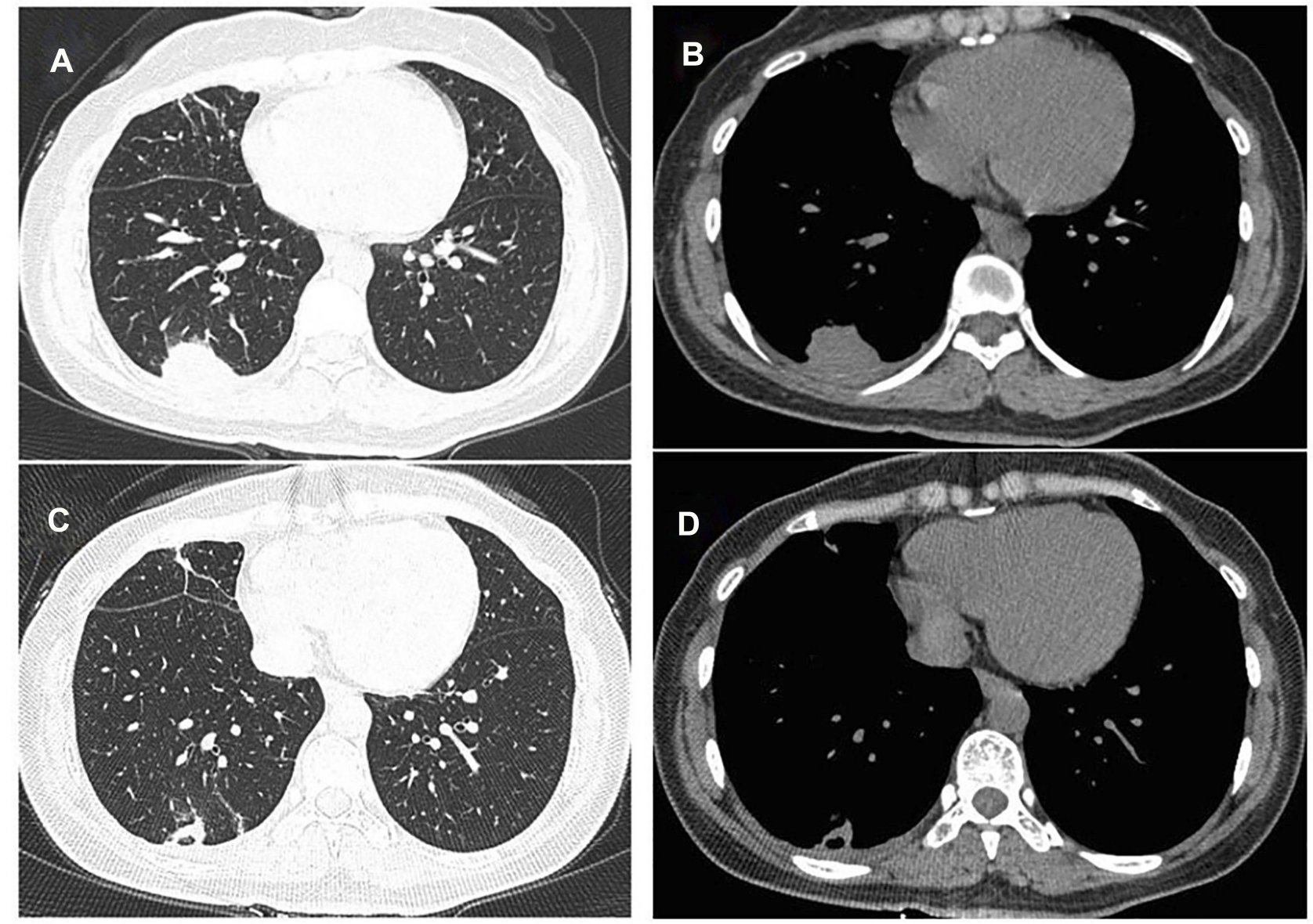

Figure 7 Case 4. CT findings in the right-inferior pulmonary lobe. (A and B) A mass measuring $3.3 \mathrm{~cm} \times 2.0 \mathrm{~cm}$ was found after three months of anti-tuberculosis therapy. (C and D) The mass was irregular with a cavity.

laboratory results were within normal ranges. The patient refused CT-guided percutaneous lung biopsy. PR was considered and the patient is followed now. The clinical characteristics of five patients are summarized in Table 1.

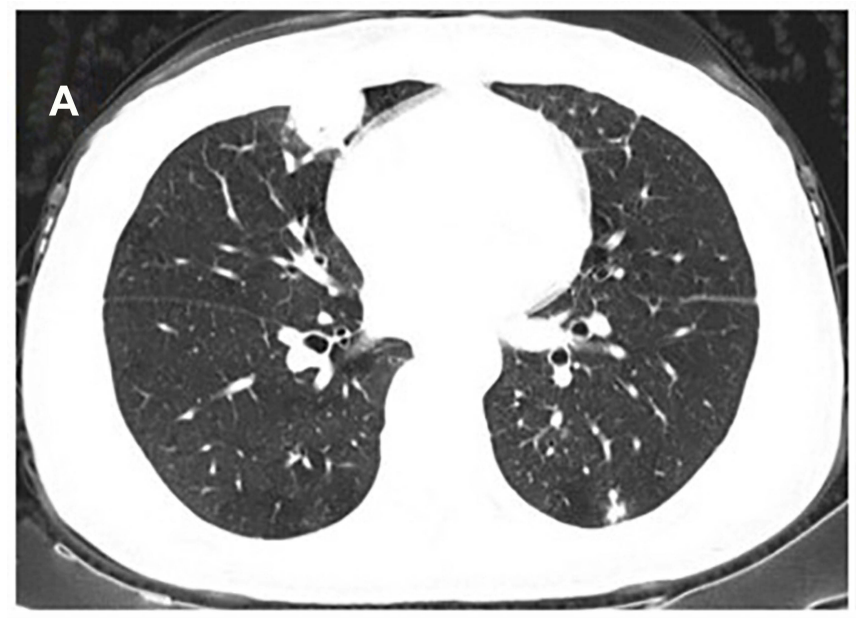

\section{Discussion}

PR is a form of tuberculosis-immune reconstitution inflammatory syndrome (TB-IRIS) that may occur during or after completion of anti-TB therapy. It represents either a paradoxical

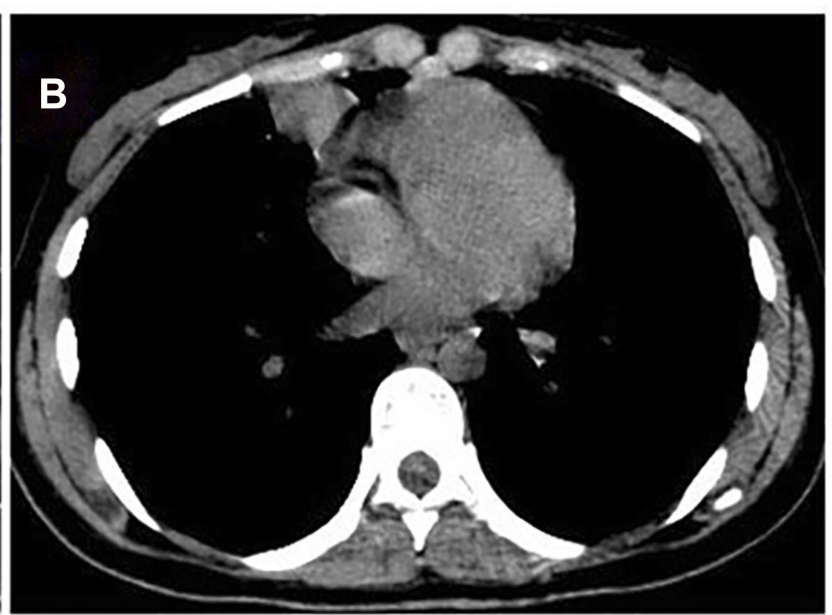

Figure 8 Case 5. CT findings in the right middle pulmonary lobe. (A and B) A $2.0 \mathrm{~cm} \times 1.5 \mathrm{~cm}$ irregular mass appeared after two months of anti-tuberculosis treatment. 
Table I The Clinical Characteristics Of Five Patients

\begin{tabular}{|c|c|c|c|c|c|c|c|c|}
\hline \multirow[t]{2}{*}{ Patient } & \multirow{2}{*}{$\begin{array}{l}\text { Age } \\
\text { (year) }\end{array}$} & \multirow[t]{2}{*}{ Gender } & \multirow{2}{*}{$\begin{array}{l}\text { Primary } \\
\text { Disease }\end{array}$} & \multicolumn{3}{|l|}{ New Mass } & \multirow{2}{*}{$\begin{array}{l}\text { Time* } \\
\text { (Months) }\end{array}$} & \multirow[t]{2}{*}{ Treatment } \\
\hline & & & & Site & $\begin{array}{l}\text { Size } \\
(\mathrm{cm})\end{array}$ & Margin & & \\
\hline I & 52 & Female & $\begin{array}{l}\text { Pulmonary } \\
\text { tuberculosis }\end{array}$ & $\begin{array}{l}\text { Right inferior } \\
\text { lobe }\end{array}$ & $3.4 \times 2.3$ & Irregular & Six & $\begin{array}{l}\text { Isoniazid, rifapentine, } \\
\text { ethambutol }\end{array}$ \\
\hline 2 & 35 & Female & $\begin{array}{l}\text { Tuberculous } \\
\text { pleuritis }\end{array}$ & $\begin{array}{l}\text { Right middle and } \\
\text { inferior lobe }\end{array}$ & $3.9 \times 2.9$ & Lobulated & Four & $\begin{array}{l}\text { Isoniazid, rifampicin, } \\
\text { ethambutol, pyrazinamide }\end{array}$ \\
\hline 3 & 17 & Female & $\begin{array}{l}\text { Pulmonary } \\
\text { tuberculosis }\end{array}$ & $\begin{array}{l}\text { Left-superior } \\
\text { lobe }\end{array}$ & $1.4 \times 0.8$ & $\begin{array}{l}\text { Irregular with } \\
\text { central low density }\end{array}$ & Six & $\begin{array}{l}\text { Isoniazid, rifampicin, } \\
\text { ethambutol, pyrazinamide }\end{array}$ \\
\hline 4 & 35 & Female & $\begin{array}{l}\text { Tuberculous } \\
\text { pleuritis }\end{array}$ & $\begin{array}{l}\text { Right inferior } \\
\text { lobe }\end{array}$ & $3.3 \times 2.0$ & Irregular with cavity & Three & $\begin{array}{l}\text { Isoniazid, rifampicin, } \\
\text { ethambutol, pyrazinamide }\end{array}$ \\
\hline 5 & 40 & Female & $\begin{array}{l}\text { Tuberculous } \\
\text { pleuritis }\end{array}$ & Right middle lobe & $2.0 \times 1.5$ & Irregular & Two & $\begin{array}{l}\text { Isoniazid, rifampicin, } \\
\text { ethambutol, pyrazinamide }\end{array}$ \\
\hline
\end{tabular}

Note: *The emergence time of new mass after anti-tuberculosis treatment.

worsening/recurring of pre-existing tuberculosis lesions or a development of new lesions in patients after effective antituberculosis treatments. ${ }^{10}$ Several criteria are needed to be taken into consideration for diagnosis of PR, including the initial response to anti-tuberculosis treatments, paradoxical deterioration of TB-related symptoms and/or radiological findings, exclusion of alternative explanations for clinical deterioration such as drug resistance, poor adherence, drug side effects and other infections. ${ }^{11}$

The five cases we reported were mainly pulmonary tuberculosis or tuberculous pleuritic. In fact, PR usually developed in patients with extrapulmonary tuberculosis. Extrapulmonary tuberculosis generally involves lymph node, central nervous system (CNS), pleura, abdomen, osteoarticular sites and disseminated tuberculosis. Breen et $\mathrm{al}^{12}$ made a retrospective study enrolling 100 patients with PR between February 1997 and February 2002. They showed that the rate of primary site of disease in extrapulmonary sites was much higher than that in lung regardless of HIV positive or negative. In another literature review ${ }^{1}$ that included a total of 122 episodes of PR from the articles between 1966 and 2001, the majority of primary lesions were also located at the extrapulmonary site, while the percentages of pulmonary tuberculosis and tuberculous pleuritis were $17.2 \%$ and $9.8 \%$, respectively.

Paradoxical response can occur with a variety of systems including CNS, respiratory system, skin and soft tissue, lymph node, abdomen, bone and tendon. ${ }^{13,14} \mathrm{PR}$ in the respiratory system is often manifested by worsening or new appearance of tuberculous effusion. ${ }^{15}$ The newly appeared pulmonary mass is infrequent and may occur in the patients with tuberculous pleural effusion. Choi et $\mathrm{al}^{16}$ retrospectively analyzed 141 patients with tuberculous pleural effusion. Of them, 16 $(11.3 \%)$ patients developed peripheral pulmonary nodule or mass in a diameter of $1-5 \mathrm{~cm}$ during anti-tuberculosis treatments. Almost all of the new lesions were ipsilateral to the side of previous effusion. The findings are in agreement with our cases. The potential cause of this phenomenon may be that invisible subpleural pulmonary tuberculosis underwent transient worsening despite anti-tuberculous medication and they became radiographically evident over time. Interestingly, one case similar to our case 1 was recently reported, in which a male patient with pulmonary tuberculosis developed a new irregularly shaped mass in the left-inferior pulmonary lobe after 6 months of anti-tuberculosis therapy. ${ }^{4}$ In another case series, ${ }^{17}$ five new lesions including ground-glass opacity and/ or consolidation were discovered during the initial treatments of pulmonary tuberculosis. The lesions were mainly in the subpleural region where the predilection sites were in accordance with the cases we presented.

When an occupation appears during the treatment of anti-tuberculosis, a few different diagnoses should be taken into consideration. First, secondary infections, in particular, fungal infection which has become one of the major complications in elderly tuberculosis patients, should be distinguished. ${ }^{18}$ Imaging of fungal infections might present as nodule, mass or both of them. The margin could be lobulated, spiculated, smooth of ill-defined, ${ }^{19}$ which would be somehow difficult to distinguish on CT scans. Second, pulmonary tumor should be ruled out as 
there are many similarities of symptoms and radiological features between both diseases. ${ }^{20}$ A large cohort of study has demonstrated that pulmonary tuberculosis is a risk factor for subsequent lung cancer in all age groups, especially in the younger patients. ${ }^{21}$ Furthermore, diseases such as rheumatism should be verified especially in female patients. Some patients of rheumatoid arthritis (RA), granulomatosis vasculitis (Wegener's) and systemic lupus erythematosus could present with the pulmonary lesions such as pulmonary nodules. Intrapulmonary nodules may occur in $<1 \%$ RA patients and particularly during the treatment of traditional disease-modifying antirheumatic drugs (DMARDs) or anti-TNF. ${ }^{22}$ The laboratory results and clinical manifestation of our five patients did not support the diseases described above, suggestive of PR.

In our series, all patients were females. Other cohort studies have shown that gender is not associated with the incidence of PR. ${ }^{12,14,23}$ To know whether the female preference in our series is related to the form of PR, as our cases all showed new mass, or is just a coincidence, further investigation is warranted. Four patients developed new mass in the right lung, which is ipsilateral to their original lesions. This phenomena is in accordance with the previous report in which PR developed on the same side with primary tuberculosis, though contralateral or bilateral lesions can also occur. ${ }^{16}$ We assume that the site of PR might be related to its pathogenesis.

The mechanisms of PR remain elusive. A few hypotheses have been proposed. Since HIV-seropositive individuals are more vulnerable to $\mathrm{PR}^{23}$ and low baseline lymphocyte counts is a widely recognized risk factor in HIV-negative patients, ${ }^{24}$ host immunodeficiency may contribute to the development of Sun et $\mathrm{al}^{25}$ have conducted a systemic study among 64 consecutive solid organ transplant recipients with tuberculosis. Nine (14.1\%) recipients developed PR which was similar to the frequency of other HIV-negative hosts. How immunodeficiency is involved in the pathogenesis of PR needs to be investigated. Rapid killing of bacilli with antibiotics may lead to the release of large amounts of microbial components, which could stimulate an exuberant inflammatory response. Higher baseline numbers of bacilli may potentiate this process and lead to $\mathrm{PR}{ }^{26} \mathrm{PR}$ might also result from the recovery from tuberculosis-induced immunosuppression which might have led to a local hypersensitive response against massive mycobacterial antigens exposure following antituberculosis treatments. ${ }^{3}$

Currently, there is no guideline regarding management for PR. As many patients have exacerbated symptoms, a combination therapy of corticosteroid and anti-tuberculosis is recommended. ${ }^{27}$ The use of corticosteroid is systemic and short term. There are no severe steroid-related complications reported. ${ }^{14}$ Some patients without apparent clinical progression continued on the original anti-tuberculosis treatments, and their pulmonary masses were diminished eventually. ${ }^{4}$ Surgical interventions including drainage and aspiration are helpful when lesions show as abscess or pleural fluid. ${ }^{1}$ Vitamin D is recognized as an immune modulator in tuberculosis infection. It may mediate PR in antituberculosis treatments. ${ }^{28}$ The patients in our cases adopted original anti-tuberculosis treatments without corticosteroid since they did not show worsening of the clinical symptoms and their general condition was good. The course of treatments should be based on the patient conditions. We extended the time of treatments according to the patients' absorption of the pulmonary masses.

\section{Conclusion}

It is necessary to consider the paradoxical reaction when a new pulmonary mass occurs during anti-tuberculosis treatments. The diagnosis should be based on the patient's clinical manifestations, laboratory results, imaging examinations and lung biopsy examinations. For patients without severe clinical symptoms, the original anti-tuberculosis therapy can be continued, and a close follow-up is needed.

\section{Ethics Statement}

The patients were fully aware that the data obtained from them were used in this study. All patients provided written informed consent for the publication of the case details and any accompanying images. The study was approved by the institutional review board of the Second Xiangya Hospital of Central-South University.

\section{Acknowledgments}

The authors are grateful to Yong Zhou, professor of University of Alabama at Birmingham, for his great help in editing English language of the manuscript. This work was supported by the National Natural Science Foundation of China under grant No. 30800503, No. 81370164 and No. 81670062; the National Natural Science Foundation of Hunan Province under grant No. 09JJ3036 and 2015JJ4087; and the National key clinical specialist construction Programs of China. The abstract of this paper was presented at the American Thoracic Society 2019 International Conference name Paradoxical Reaction in The Form of New Pulmonary Mass During Anti tuberculosis Treatment: a Case Report And Review of The 
Literature as a poster presentation with interim findings. The presentation details are available online: https://www.atsjour nals.org/doi/abs/10.1164/ajrccm-conference.2019.199.1 MeetingAbstracts.A5138

\section{Disclosure}

The authors report no conflicts of interest in this work.

\section{References}

1. Cheng V, Ho P, Lee R, et al. Clinical spectrum of paradoxical deterioration during antituberculosis therapy in non-HIV-infected patients. Eur $J$ Clin Microbiol Infect Dis. 2002;21:803-809. doi:10.1007/s10096-0020821-2

2. Bhattacharya A, Mukherjee S. Paradoxical reaction in the form of pleural effusion after onset of anti-tuberculous medication for tubercular lymphadenitis. Clin Med. 2017;17:143-145. doi:10.7861/clinmedicine.17-2-143

3. Shinohara T, Kagawa K, Okano Y, et al. Disseminated tuberculosis after pregnancy progressed to paradoxical response to the treatment: report of two cases. BMC Infect Dis. 2016;16:284. doi:10.1186/ s12879-016-1624-x

4. Okazaki A, Watanabe S, Yoneda T, et al. Paradoxical reaction to antituberculosis therapy after 6 months of treatment for pulmonary tuberculosis: a case report. J Infect Chemother. 2016;22:748-751. doi:10.1016/j.jiac.2016.03.012

5. VCC C. Paradoxical response during anti-tuberculosis therapy. Hong Kong Med J. 2006;11:20-21.

6. Cheng SL, Wang HC, Yang PC. Paradoxical response during antituberculosis treatment in HIV-negative patients with pulmonary tuberculosis. Int J Tuberc Lung Dis. 2007;11:1290-1295.

7. Hawkey CR, Yap T, Pereira J, et al. Characterization and management of paradoxical upgrading reactions in HIV-uninfected patients with lymph node tuberculosis. Clin Infect Dis. 2005;40:1368-1371. doi: $10.1086 / 429317$

8. Wendel KA, Alwood KS, Gachuhi R, et al. Paradoxical worsening of tuberculosis in HIV-infected persons. Chest. 2001;120:193-197. doi:10.1378/chest.120.1.193

9. NARITA M, ASHKIN D, HOLLENDER ES, PITCHENIK AE. Paradoxical worsening of tuberculosis following antiretroviral therapy in patients with AIDS. Am J Respir Crit Care Med. 1998;158:157-161. doi:10.1164/ajrccm.158.1.9712001

10. Lanzafame M, Vento S. Tuberculosis-immune reconstitution inflammatory syndrome. J Clin Tuberc Other Mycobact Dis. 2016;3:6-9. doi:10.1016/j.jctube.2016.03.002

11. Meintjes G, Lawn SD, Scano F, et al. Tuberculosis-associated immune reconstitution inflammatory syndrome: case definitions for use in resource-limited settings. Lancet Infect Dis. 2008;8:516-523. doi:10.1016/S1473-3099(08)70184-1

12. Breen RAM, Smith CJ, Bettinson H, et al. Paradoxical reactions during tuberculosis treatment in patients with and without HIV coinfection. Thorax. 2004;59:704-707. doi:10.1002/cncr.25616
13. Singh U, Mohan V, Ramaraj M. Areekkara P, Deshawar S. Varied presentations of paradoxical upgrading reactions in pulmonary tuberculosis. Medicine. 2016;5.

14. Geri G, Passeron A, Heym B, et al. Paradoxical reactions during treatment of tuberculosis with extrapulmonary manifestations in HIV-negative patients. Infection. 2013;41:537-543. doi:10.1007/s15010-012-0376-9

15. Al-Majed SA. Study of paradoxical response to chemotherapy in tuberculous pleural effusion. Respir Med. 1996;90:211-214. doi:10.1016/S0954-6111(96)90289-9

16. Choi YW, Jeon SC, Seo HS, et al. Tuberculous pleural effusion: new pulmonary lesions during treatment. Radiology. 2002;224:493-502. doi:10.1148/radiol.2242011280

17. Akira M, Sakatani M, Ishikawa H. Transient radiographic progression during initial treatment of pulmonary tuberculosis: CT findings. J Comput Assist Tomogr. 2000;24:426-431. doi:10.1097/00004728200005000-00014

18. Ren X. Liu W and Liu Y. Effects of fluconazole on the clinical outcome and immune response in fungal co-infected tuberculosis patients. Microb Pathogen. 2018;117:148-152. doi:10.1016/j.micpath.2018.02.015

19. Guimarães MD, Marchiori E, de Souza Portes Meirelles G, et al. Fungal infection mimicking pulmonary malignancy: clinical and radiological characteristics. Lung. 2013;191:655-662. doi:10.1007/ s00408-013-9506-0

20. Bhatt MLB, Kant S, Bhaskar R. Pulmonary tuberculosis as differential diagnosis of lung cancer. South Asian J Cancer. 2012;1:36-42. doi:10.4103/2278-330X.96507

21. Wu C-Y, Hu H-Y, Pu C-Y, et al. Pulmonary tuberculosis increases the risk of lung cancer. Cancer. 2011;117:618-624.

22. Kovács A, Baksay B, Cserenyecz A, et al. Occurrence of pulmonary rheumatoid nodules following biological therapies. Clin Rheumatol. 2015;34:1639-1642. doi:10.1007/s10067-014-2789-6

23. Brown CS, Smith CJ, Breen RAM, et al. Determinants of treatmentrelated paradoxical reactions during anti-tuberculosis therapy: a case control study. BMC Infect Dis. 2016;16:479. doi:10.1186/s12879-0161816-4

24. Cheng VCC, Yam WC, Woo PCY, et al. Risk factors for development of paradoxical response during antituberculosis therapy in HIV-negative patients. Eur J Clin Microbiol Infect Dis. 2003;22:597-602. doi:10.1007/s10096-003-0998-Z

25. Sun H-Y, Munoz P, Torre-Cisneros J, et al. Mycobacterium tuberculosisassociated immune reconstitution syndrome in solid-organ transplant recipients. Transplantation. 2013;95:1173-1181. doi:10.1097/TP.0b01 3e31828719c8

26. Desch AN, Gibbings SL, Goyal R, et al. Flow cytometric analysis of mononuclear phagocytes in nondiseased human lung and lung-draining lymph nodes. Am J Respir Crit Care Med. 2015;193:614-626. doi:10.1164/rcem.201507-1376OC

27. Xie YL, Rosen LB, Sereti I, et al. Severe paradoxical reaction during treatment of disseminated tuberculosis in a patient with neutralizing anti-IFN $\gamma$ autoantibodies. Clin Infect Dis. 2016;62:770-773. doi:10.1093/cid/civ995

28. Barr D, Coussens A, Irvine S, et al. Paradoxical upgrading reaction in extra-pulmonary tuberculosis: association with vitamin D therapy. Int J Tuberc Lung Dis. 2017;21:677-683. doi:10.5588/ijtld.16.0927
Infection and Drug Resistance

\section{Publish your work in this journal}

Infection and Drug Resistance is an international, peer-reviewed openaccess journal that focuses on the optimal treatment of infection (bacterial, fungal and viral) and the development and institution of preventive strategies to minimize the development and spread of resistance. The journal is specifically concerned with the epidemiology of antibiotic resistance and the mechanisms of resistance development and diffusion in both hospitals and the community. The manuscript management system is completely online and includes a very quick and fair peerreview system, which is all easy to use. Visit http://www.dovepress.com/ testimonials.php to read real quotes from published authors. 